\title{
A rare case of quadrigeminal plate lipoma presenting with the sixth cranial nerve palsy
}

\author{
${ }^{1}$ Department of Neurosurgery, Bangabandhu Sheikh Mujib Medical University, Shahbag, Dhaka 1000, Bangladesh. \\ ${ }^{2}$ Department of Emergency and Casualty, Bhawani Hospital, Birgunj 44300, Nepal. \\ ${ }^{3}$ Department of Nephrology, Golden Hospital Pvt. Ltd., Hospital Chowk, Biratnagar 56613, Nepal. \\ ${ }^{4}$ Department of Neurosurgery, Bezmialem Vakıf Universty, İstanbul 34265, Turkey.
}

Bipin Kumar Chaurasia1, Narendra Shalike1, Silak Ram Chaudhary1, Shamsul Alam¹, Dhiman Chowdhory ${ }^{1}$, Kanak Kanti Barua1, Ranjit Kumar Chaurasiya', Raushan Kumar Chaurasia ${ }^{2}$, Ramesh Kumar Chaurasia ${ }^{3}$, Tolga Dundar ${ }^{4}$

Correspondence to: Dr. Bipin Kumar Chaurasia, Department of Neurosurgery, Bangabandhu Sheikh Mujib Medical University, Kazi Nazrul Islam Avenue, Shahbag, Dhaka 1000, Bangladesh. E-mail: trozexa@gmail.com

How to cite this article: Chaurasia BK, Shalike N, Chaudhary SR, Alam S, Chowdhory D, Barua KK, Chaurasiya RK, Chaurasia RK, Chaurasia RK, Dundar T. A rare case of quadrigeminal plate lipoma presenting with the sixth cranial nerve palsy. Neuroimmunol Neuroinflammation 2017;4:232-5.

Article history:

Received: 14 Aug 2017

Accepted: 6 Sep 2017

Published: 9 Nov 2017

Key words:

Lipoma,

quadrigeminal plate,

the 6th cranial nerve palsy,

hydrocephalus

\section{ABSTRACT}

Intracranial lipomas are rare benign tumour that is slow growing, generally asymptomatic, most frequently located in the midline areas and are usually an incidental finding on imaging and therefore cases are not frequently reported. This study reports a case of a patient with quadrigeminal plate lipoma presenting with obstructive hydrocephalous and the 6th cranial nerve palsy that was successfully treated with ventriculo-peritoneal shunting without addressing the lesion.

\section{INTRODUCTION}

Intracranial lipomas are very uncommon slow growing benign tumor with an incidence of less than $0.1 \%$ of all intracranial tumors usually found incidentally in autopsy or whenever computed tomography (CT) or magnetic resonance imaging (MRI) is advised for an alternative reason. Intracranial lipomas are generally congenital, benign malformations and most frequently located in the midline areas ${ }^{[1]}$. CT and MRI are usually sufficient for diagnosis of lipomas because of very low attenuation value on $\mathrm{CT}$ and short $\mathrm{T} 1$ and $\mathrm{T} 2$ on
MRI and therefore histopathological confirmation is practically not required. We report a case of 19-yearold male who came to us with the 6th nerve palsy and diagnosed as quadrigeminal plate lipoma. We describe $\mathrm{CT}$ and MRI findings with brief review of literature.

\section{CASE REPORT}

A 19-year-old male, a student of grade XII was referred to our department with the complaint of headache for 2 years, multiple episodes of vomiting, visual disturbances

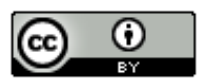

This is an open access article licensed under the terms of Creative Commons Attribution 4.0 International License (https://creativecommons.org/licenses/by/4.0/), which permits unrestricted use, distribution, and reproduction in any medium, as long as the original author is credited and the new creations are licensed under the identical terms.

For reprints contact: service@oaepublish.com

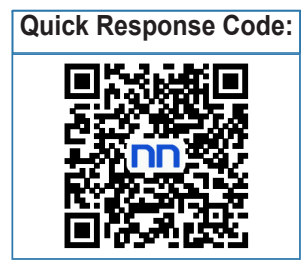


and diplopia for 2 months. He also complained of generalized weakness since childhood. There was no history of seizure, loss of consciousness or behavioural changes. On examination, it revealed normal general condition having all systemic examinations within normal except nervous system examination where we found diplopia, the 6th cranial nerve palsy on right side [Figure 1] and bilateral papilloedema on fundoscopic examination.

All laboratory finding including that for fitness for being under general anaesthesia were normal. CT of head revealed a rounded well defined fat density [density-101 Hounsfield units $(\mathrm{HU})$ ] area measuring about $17.6 \mathrm{~mm} \times$ $20.6 \mathrm{~mm}$ in the region of quadrigeminal cistern [Figure 2].

MRI findings suggested a rounded well defined hyperintensity lesion measuring about $2.1 \mathrm{~cm} \times 1.9 \mathrm{~cm}$ in the region of quadrigeminal cistern in T1-W, T2-W [Figure $3 A$ and $B]$ and fluid attenuated inversion recovery images (FLAIR) sequences [Figure 4] and the lesion didn't take contrast enhancement [Figure 3C] and diffusion weighted image (DWI) sequence suggested no restriction of diffusion [Figure 3D]. The lesion caused compression over cerebral aqueduct resulting in dilation of the 3rd and lateral ventricles. Septum pellucidum was found to be absent [Figure 4]. We diagnosised that this patient had a quadrigeminal plate cistern lipoma with obstructive hydrocephalous due to aqueductal stenosis. Thus, we performed a ventriculoperitoneal shunting using right Kocher's point and the cerebrospinal fluid (CSF) pressure was found to be elevated. Postoperative state was uneventful and following ventriculo-peritoneal shunting, the 6th cranial nerve palsy was resolved and the headache got subsided gradually.

\section{DISCUSSION}

Intracranial lipomas constitute approximately $0.1 \%$

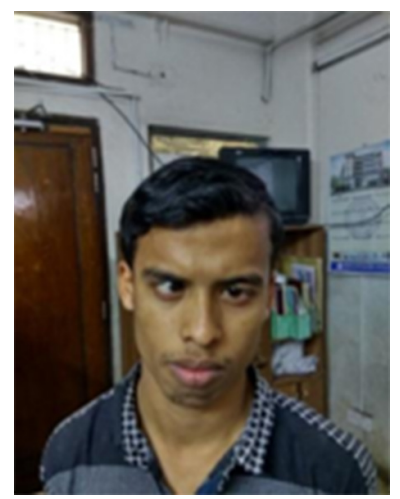

Figure 1: Showing the case with the 6th cranial nerve palsy on right side (the photograph was taken with the informed written consent of the patient) of all intracranial tumours. These benign lesions are thought to arise from differentiation of the meninx primitiva, a mesenchymal derivative of neural crest, to lipoma tissue. The vast majority of these types of lesions occur near the midline ${ }^{[1]}$. More than $50 \%$ have been reported to be associated with congenital brain malformations such as agenesis or hypoplasia of the corpus callosum ${ }^{[2]}$. Others include the absence of the septum pellucidum, cranium bifidum, spina bifida, myelomeningocele, hypoplasia of the vermis and malformation of the cortex ${ }^{[1]}$. In this case, we found that the septum pallucidum was absent [Figure 4].

The frequency of intracranial lipomas according to location are as following: corpus callosum (64\%), quadrigeminal-ambient cistern (13\%), infundibularchiasmatic region $(13 \%)$, cerebellopontine angle $(0.06 \%)$ and Sylvian fissure $(0.03 \%)^{[3]}$. Eighty percent of cerebellopontine angle lesions, $50 \%$ of callosal, $50 \%$ of Sylvian fissure and $20 \%$ of quadrigeminal-ambient cistern lipomas become symptomatic ${ }^{[2]}$. Intracranial lipomas are generally asymptomatic lesions and are usually an incidental finding on imaging. Symptomatic lesions are very rare and the symptoms differ per the lipoma's location. Persistent headaches, convulsions ${ }^{[4,5]}$, psychomotor retardation and cranial nerve defects may occur $^{[6]}$.

Symptoms are presented in $20 \%$ of cases of lipoma of quadrigeminal plate ${ }^{[7]}$. The common neurologic findings are features of raised intracranial pressure and hydrocephalous which can be managed easily with ventriculoperitoneal shunting or similar procedures used to treat excess $\mathrm{CSF}^{[8]}$. Most cases of intracranial lipoma involve children and young adults as we had a young teen male presented with intracranial lipoma ${ }^{[9]}$.

Although most of lipoma found incidentally and causes no symptoms and require no intervention ${ }^{[8]}$, our case had triventriculomegaly with features of raised

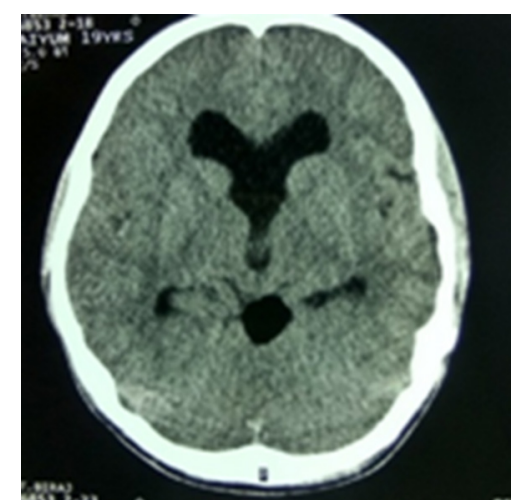

Figure 2: Computed tomography scan of head showing a rounded well defined fat density (density 101) lesion in the region of quadrigeminal cistern 

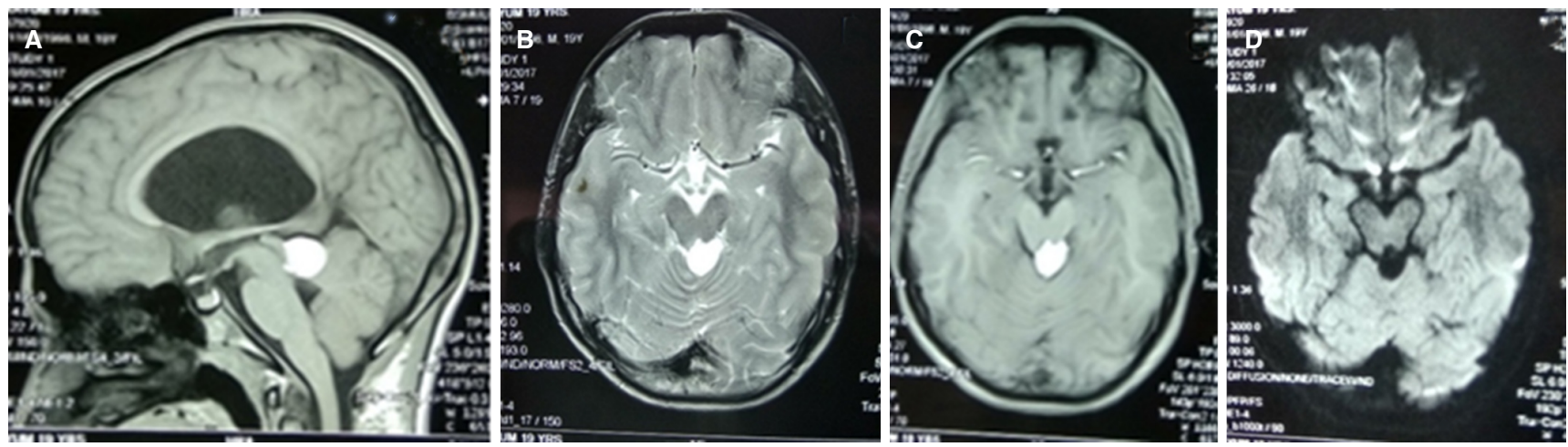

Figure 3: Magnetic resonance imaging of the brain: $(A)$ sagittal T1-weighted (T1-W) sequence showing hyperintense mass over quadrigeminal plate; $(B)$ axial T2-W sequence with hyperintense mass; $(C)$ axial T1-W sequence with contrast showing no contrast enhancement of the lesion; (D) axial DWI sequence showing no restriction of diffusion by the mass. DWI: diffusion weighted image



Figure 4: Magnetic resonance imaging of brain with FLAIR sequence showing hyperintense lesion over quadrigeminal cistern with triventriculomegaly and absent septum pellucidum. FLAIR: fluid attenuated inversion recovery images

intracranial pressure and the 6th nerve palsy [Figure 1]. The signs of raised intracranial pressure were thought to be secondary to hydrocephalus which was evident in the case reported on MRI as enlargement of the 3rd ventricle and temporal horns of the lateral ventricles [Figure 4]. On CT, lipomas demarcate areas of marked hypodensity that did not show enhancement after administration of intravenous contrast. They usually have a CT density of between -50 and $-100 \mathrm{HU}$. Calcification is often present in interhemispheric lipomas - usually within the fibrous capsule surrounding the lesion ${ }^{[10]}$. MRI showed a homogeneous, hyperintense mass on T1-weighted (T1-W) images which where hypo- intense with fat suppression, hyperintense on T2-W images and hypointense on $\mathrm{T} 2^{*}-\mathrm{W}$ images (due to a magnetic susceptibility and chemical shift effects), no enhancement. Vascular imaging (three-dimensional time-of-flight or MR angiography) may show arterial abnormalities. Dermoids, teratoma, lipomatous transformation of neoplasm or subacute hemorrhage should all be considered in a differential diagnosis ${ }^{[10]}$.

The imaging characteristics of lipomas are very similar to those of dermoid tumours. On CT, both these lesions appear hypodense and neither enhances with contrast. The density of lipomas ranges from 50 to $100 \mathrm{HU}$, 
whereas the density of dermoid tumours ranges from 20 to $40 \mathrm{HU}$. On MRI, both lesions exhibit high signal intensity on T1-W images and low signal intensity on T2-W images. However, due to the presence of skin appendages and hair, dermoid tumours may be nonhomogeneous on $\mathrm{MR}^{[11,12]}$.

In our case, the CT of head revealed a rounded well defined fat density (density-101 HU) lesion in the region of quadrigeminal cistern [Figure 2]. MRI findings suggested a rounded well defined hyperintensity lesion in the region of quadrigeminal cistern in T1W, T2-W [Figure 3A and B] and FLAIR sequences [Figure 4] without contrast enhancement [Figure 3C] and no restriction of diffusion in DWI sequences [Figure 3D]. The lesion caused compression over cerebral aqueduct resulting in dilation of the 3rd and lateral ventricles. Septum pellucidum was found to be absent [Figure 4]. Treatment of intracranial lipoma depends on the size and location of tumour and can be managed conservatively and surgically if the tumour is causing an mass effect ${ }^{[13]}$. Primary objectives in the management of quadrigeminal region lipomas include obtaining definitive histology of the lesion, normalizing CSF dynamics, achieving maximum lesion excision and relieving local pressure effects ${ }^{[2]}$. Radical surgical extirpation is usually contraindicated for 2 reasons. First, the lipoma's generally dense vasculature tends to adhere to the surrounding neural tissue in general and the cranial nerves in particular - making resection technically difficult and thus hazardous. Second, lipomas do not usually involve a mass effect on brain tissue; surgery is unnecessary for stable or asymptomatic cases, since the risks far outweigh the potential benefits ${ }^{[6]}$.

As is true for all intracranial lipomas, conservative management for a lipoma located in the quadrigeminal cistern is reasonable unless the patient becomes symptomatic. Our case was having features of raised intracranial pressure with the 6th cranial nerve palsy and obstructive hydrocephalus due to aqueductal stenosis, we performed ventriculo-peritoneal shunting and the patient was improving gradually. A quadrigeminal plate lipoma occasionally present with hydrocephalous due to aqueductal stenosis which can be managed with CSF diversion procedures. We did ventriculo-peritoneal shunting and our result was satisfactory. To my best knowledge this is the first case of quadrigeminal plate lipoma in South Asian Region presented to us having with features of raised intracranial pressure, the 6th nerve palsy, obstructive hydrocephalus and absent septum pellucidum.

\section{DECLARATIONS}

\section{Authors' contributions}

Conception, diagnosis and design: B.K. Chaurasia

Manuscript preparation: N. Shalike, S.R. Chaudhary

Radiology diagnosis: S. Alam, D. Chowdhory, K.K. Barua, T. Dundar

Literature search: N. Shalike, R.K. Chaurasiya

Technical revision: R.K. Chaurasia, R.K. Chaurasia

Manuscript editing: S. Alam, K.K. Barua

Manuscript revision: B.K. Chaurasia

Final approval of manuscript: B.K. Chaurasia

\section{Financial support and sponsorship} None.

\section{Conflicts of interest}

There are no conflicts of interest.

\section{Patient consent \\ Patient consent was obtained from the patient.}

\section{Ethics approval}

There is no ethics issue in this paper.

\section{REFERENCES}

1. Jabot G, Stoquart-Elsankari S, Saliou G, Toussaint P, Deramond H, Lehmann P. Intracranial lipomas: clinical appearances on neuroimaging and clinical significance. J Neurol 2009;256:851-5.

2. Yilmaz N, Unal O, Kiymaz N, Yilmaz C, Etlik O. Intracranial lipomas--a clinical study. Clin Neurol Neurosurg 2006;108:363-8.

3. Maiuri F, Cirillo S, Simonetti L, De Simone MR, Gangemi M. Intracranial lipomas. Diagnostic and therapeutic considerations. $J$ Neurosurg Sci 1988;32:161-7.

4. Guye M, Gastaut JL, Bartolomei F. Epilepsy and perisylvian lipoma/ cortical dysplasia complex. Epileptic Disord 1999;1:69-73.

5. Loddenkemper T, Morris HH 3rd, Diehl B, Lachhwani DK. Intracranial lipomas and epilepsy. J Neurol 2006;253:590-3.

6. Yildiz H, Hakyemez B, Koroglu M, Yesildag A, Baykal B. Intracranial lipomas: importance of localization. Neuroradiology 2006;48:1-7.

7. Ono J, Ikeda T, Imai K, Mano T, Matsuoka T, Nagai T, Okada S. Intracranial lipoma of the quadrigeminal region associated with complex partial seizures. Pediatr Radiol 1998;28:729-31.

8. Nikaido Y, Imanishi M, Monobe T. Lipoma in the quadrigeminal cistern-case report. Neurol Med Chir (Tokyo) 1995;35:175-8.

9. Hayashi T, Shojima K, Yamamoto M, Hashimoto T, Fukuzumi A, Honda E. Intracranial lipomas--report of six cases. No To Shinkei 1983;35:25768. (in Japanese)

10. Osborn A, Blaser S, Salzman K, Provenzale J, Castillo M, Hedlund GL. Diagnostic Imaging: Brain. Salt Lake City: Amirsys; 2005. p. I-1-22-5.

11. Kazner E, Stochdorph O, Wende S, Grumme T. Intracranial lipoma Diagnostic and therapeutic considerations. J Neurosurg 1980;52:234-45.

12. Feldman RP, Marcovici A, LaSala PA. Intracranial lipoma of the sylvian fissure. Case report and review of the literature. J Neurosurg 2001;94:515-9.

13. Ogbole G, Kazaure I, Anas I. Quadrigeminal plate cistern lipoma. BMJ Case Rep 2009;2009:2110. 